Research Article

\title{
Preparation and Study of Multi-Heteroatom Carbon Nanotube as Excellent Electrocatalyst for Oxygen Reduction Reaction Using Polydopamine Derivative
}

\author{
Jian Yang $\mathbb{D}^{1,2}$ Lihong Niu, ${ }^{3}$ Zhijun Zhang $\mathbb{D}^{1},{ }^{1}$ Liang Yan, ${ }^{2}$ and Lingjun $\mathrm{Chou}^{2}$ \\ ${ }^{1}$ Engineering Research Center for Nanomaterials, Henan University, Kaifeng 475004, China \\ ${ }^{2}$ State Key Laboratory for Oxo Synthesis and Selective Oxidation, Lanzhou Institute of Chemical Physics, \\ Chinese Academy of Sciences, Lanzhou 730000, China \\ ${ }^{3}$ The Key Laboratory for Special Functional Materials of MOE, Henan University, Kaifeng 475004, China \\ Correspondence should be addressed to Zhijun Zhang; zhangzhijun@henu.edu.cn
}

Received 18 October 2017; Revised 26 March 2018; Accepted 16 April 2018; Published 22 May 2018

Academic Editor: Peter Majewski

Copyright (c) 2018 Jian Yang et al. This is an open access article distributed under the Creative Commons Attribution License, which permits unrestricted use, distribution, and reproduction in any medium, provided the original work is properly cited.

F and other heteroatom codoped multiwalled carbon nanotubes as nonmetal electrocatalyst were developed through pyrolysis of polydopamine derivative under high temperature. The influence of the amount and type of heteroatom on the catalytic activity was investigated. Especially, N/S/F-codoped carbon nanotubes exhibit the most excellent electrocatalytic activity for oxygen reduction reaction and stability. The method afforded an excellent building block to universally design multi-heteroatom-doped or F-doped carbon materials for ORR or other energy-relevant applications.

\section{Introduction}

To date, Pt-based materials are preferably used as the electrocatalyst for fuel cell because of the low over potential and high current density [1-3], though Pt-based catalysts as precious metal are expensive and their kinetics of the oxygen reduction reaction (ORR) is sluggish.

To overcome the above problem, the nonmetal catalysts with similar activity of oxygen reduction reaction and superior long-time durability compared to $\mathrm{Pt}-\mathrm{C}$ catalyst become the focus of proton exchange membrane fuel cell in recent years [4-6]. Among them, heteroatom-doped carbon has attracted intensive attention due to excellent catalytic performance, high stability, and low cost, such as nitrogen, sulfur, boron, phosphorus, fluorine, and so on [7-12]. These heteroatom-doped carbon materials emerged one after another for metal-free catalytic technology. Afterwards, dual or multiple doped carbon materials were studied for further enhancement in the catalytic activity due to the synergistic effect of different heteroatoms, such as N/S, N/B, N/P, N/I, $\mathrm{N} / \mathrm{B} / \mathrm{P}$, and so on [13-17]. Meanwhile, researchers found that F-doped carbon materials showed the promising ORR performance because $\mathrm{F}$ atom affected greatly the electronic properties of carbon materials [9]. Few literatures about F-doped or codoped carbon materials were reported because of the difficult preparing process.

Polydopamine as a carbon resource to form carboncoated materials has been investigated in the previous work because of its strong molecule designability and easy deposition on substrates [18] such as $\mathrm{CN}_{x}$ electrocatalyst; $\mathrm{N}, \mathrm{S}$ doped graphene; and so on $[19,20]$.

Based on these studies, we developed firstly a novel route to prepare $\mathrm{F}$ and other heteroatom codoped carbon-based catalyst and study the influence of the kind and the amount of heteroatom on the ORR activity.

\section{Materials and Methods}

First, carboxylic MWCNTs were dispersed uniformly in $\mathrm{pH}$ 8.5 Tris- $\mathrm{HCl}$ buffer solution through the ultrasonic method for $1 \mathrm{~h}$. Then, the polydopamine was deposited on MWCNTs after the addition of $0.2 \mathrm{mg} / \mathrm{mL}$ of dopamine hydrochloride 


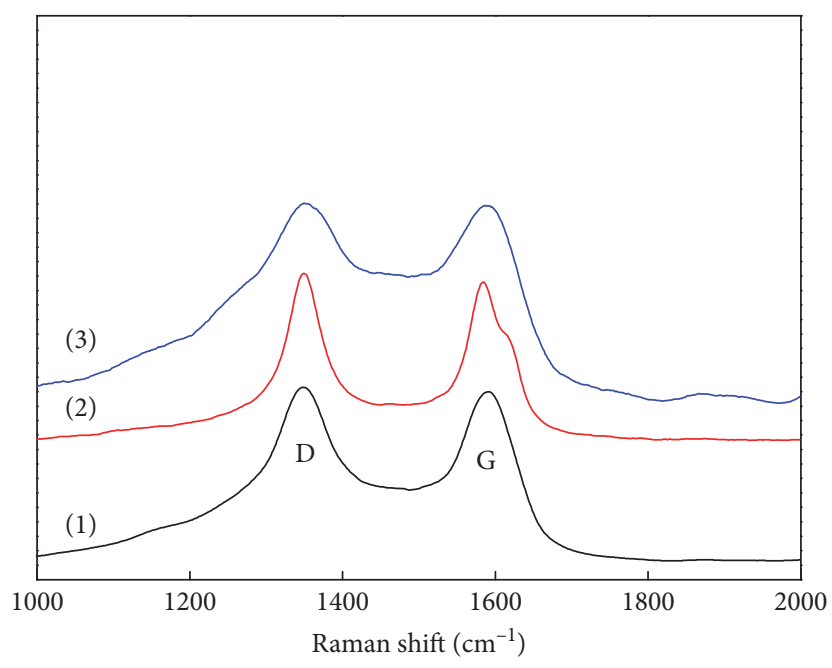
(1) N/S-CNTs $I_{\mathrm{D}} / I_{\mathrm{G}}=1.07$
$\sigma=1.10 \mathrm{~S} / \mathrm{cm}$
(2) N/S/F-CNTs-2 $I_{\mathrm{D}} / I_{\mathrm{G}}=0.93$
$\sigma=0.56 \mathrm{~S} / \mathrm{cm}$
(3) $\mathrm{N} / \mathrm{S} / \mathrm{F}-\mathrm{CNTs} I_{\mathrm{D}} / I_{\mathrm{G}}=1.10$
$\sigma=1.19 \mathrm{~S} / \mathrm{cm}$

Figure 1: Raman spectra of the catalysts.

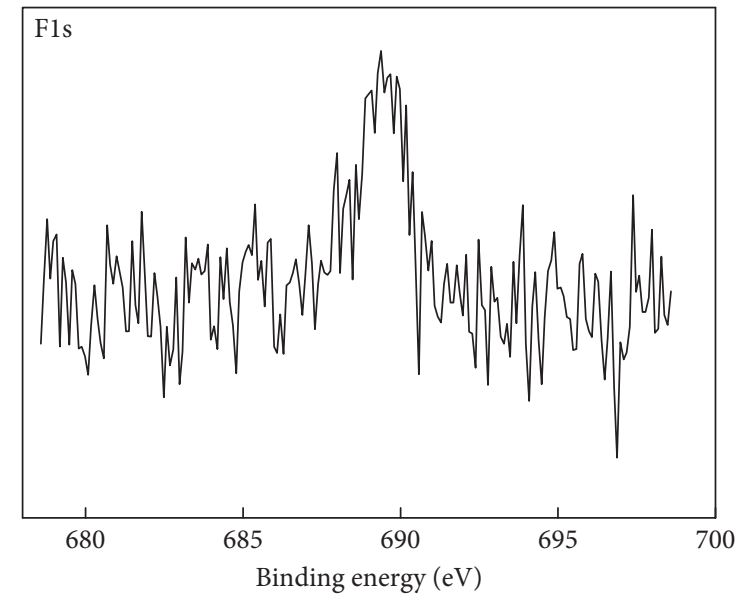

(a)

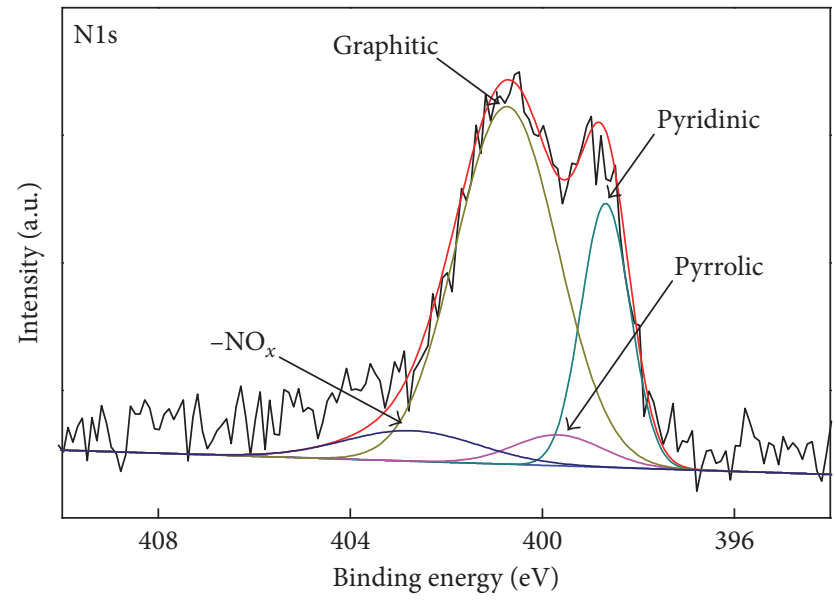

(b)

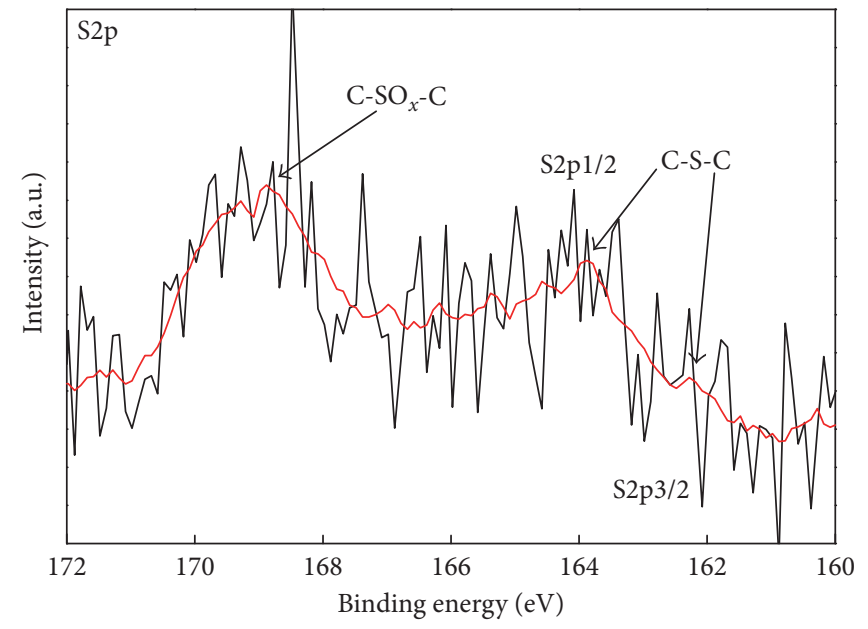

(c)

FIgURE 2: F1s, N1s, and S2p XPS spectra of N/S/F-CNTs-2. 


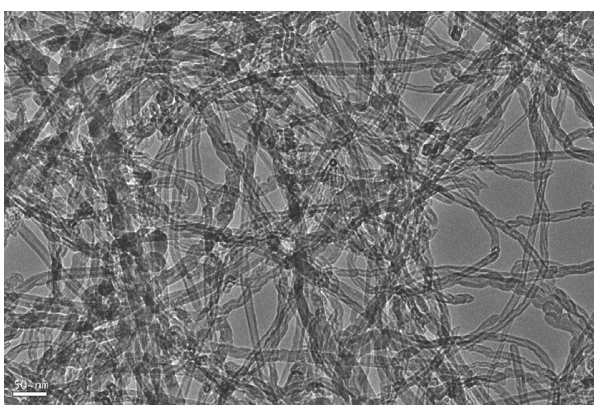

(a)

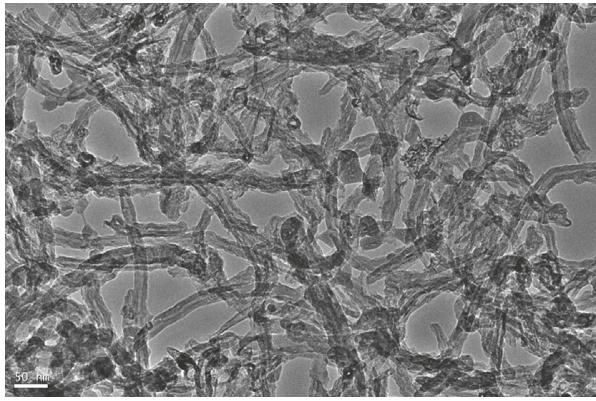

(c)

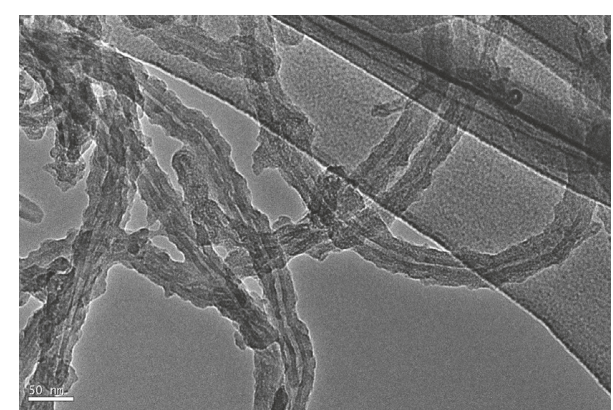

(b)

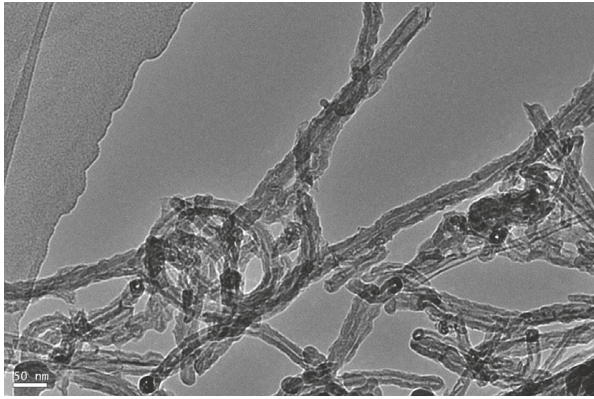

(d)

Figure 3: TEM of the samples: (a) carboxylic MWCNTs; (b) CNTs-Pdop-S( $\left.\mathrm{CF}_{2}\right)_{7} \mathrm{CF}_{3}$; (c) N/S/F-CNTs; (d) N/S-CNTs. The inserted scale bar is $50 \mathrm{~nm}$.

in the above solution under stirring continuously at room temperature for $24 \mathrm{~h}$. Afterwards, CNTs-modified polydopmaine, named PDA-CNTs, were obtained by centrifugation, washing, and drying in succession.

PDA-CNTs were dispersed uniformly into anhydrous $\mathrm{CH}_{2} \mathrm{Cl}_{2}$ through the ultrasonic method. Then, 1-octanethiol (or $1 \mathrm{H}, 1 \mathrm{H}^{\prime}, 2 \mathrm{H}, 2 \mathrm{H}^{\prime}$-perflurooctanethiol) and anhydrous triethylamine were added to the solution under $\mathrm{N}_{2}$ atmosphere for $24 \mathrm{~h}$. The obtained CNT-PDA-S $\left(\mathrm{CH}_{2}\right)_{7} \mathrm{CH}_{3}$ or CNT-PDA-S $\left(\mathrm{CF}_{2}\right)_{7} \mathrm{CF}_{3}$ was centrifuged, rinsed, and dried. Finally, the sample was heated at $800^{\circ} \mathrm{C}$ under $\mathrm{N}_{2}$ for $2 \mathrm{~h}$ to obtain N, S codoped CNTs or N, S, F codoped CNTs, named N/S-CNTs or N/S/F-CNTs. For the comparison of the electrocatalytic activity, PDA-CNTs were also heated under the same condition to prepare $\mathrm{N}$-doped MWCNTs, named $\mathrm{N}$-CNTs. Also, CNT-PDA-S $\left(\mathrm{CF}_{2}\right)_{7} \mathrm{CF}_{3}$ was pyrolyzed at $600^{\circ} \mathrm{C}$ under $\mathrm{N}_{2}$ for $2 \mathrm{~h}$, named N/S/F-CNTs-2.

The morphologies of the samples were observed by field emission transmission electron microscopes (FEI Tecnai G2 F20). The component of the carbon material was analyzed on Raman microscope (Renishaw InVia). X-ray photoelectron spectra (XPS) were recorded on ESCALAB 250Xi (Thermo Fisher Scientific) to analyze the compositions of the support and the electrocatalyst, and all the binding energies were calibrated to $\mathrm{C} 1 \mathrm{~s}$ peak at $284.8 \mathrm{eV}$. Electrochemical tests were carried out by $\mathrm{CHI} 660 \mathrm{E}$ electrochemical workstation in a standard three-electrode system. The working electrode was prepared by pasting electrocatalyst inks on a glassy carbon rotating disk electrode with the diameter of $3 \mathrm{~mm}$. The ink contained $5 \mathrm{mg}$ of catalysts, $30 \mu \mathrm{L}$ of $5 \mathrm{wt} . \%$ Nafion solution, and $1 \mathrm{~mL}$ ethanol. $5 \mu \mathrm{L}$ ink was dropped on the surface of the glassy carbon electrode. The counter electrode was a platinum wire with the diameter of $0.5 \mathrm{~mm}$, and the SCE electrode was served as a reference electrode. Cyclic voltammetry was performed from 0.1 to $-0.5 \mathrm{~V}$ at $5 \mathrm{mV} / \mathrm{s}$ in $\mathrm{O}_{2}$-saturated or $\mathrm{N}_{2}$-saturated $0.1 \mathrm{M} \mathrm{KOH}$ solution. Using the rotating ring disk electrode with the diameter of $3 \mathrm{~mm}$, linear sweep voltammetry was performed from 0.1 to $-0.5 \mathrm{~V}$ at a scan rate of $10 \mathrm{mV} / \mathrm{s}$ with the rotational speed from 400 to $2000 \mathrm{rpm}$ in the $\mathrm{O}_{2}$-saturated $0.1 \mathrm{M} \mathrm{KOH}$ solution.

\section{Results and Discussions}

There were two typical peaks measured at $1350 \mathrm{~cm}^{-1}$ and $1590 \mathrm{~cm}^{-1}$ in all the Raman spectra corresponding to D and $\mathrm{G}$ bands, respectively (Figure 1). The intensity of $\mathrm{D}$ band and $\mathrm{G}$ band ratio $\left(I_{\mathrm{D}} / I_{\mathrm{G}}\right)$ can be used to assess the defect quantity and disorder of the structure. The $I_{\mathrm{D}} / I_{\mathrm{G}}$ value increased from N/S-CNTs to N/S/F-CNTs obtained at the same temperature, which means that the heteroatom increased the disorder. In addition, $I_{\mathrm{D}} / I_{\mathrm{G}}$ of N/S/F-CNTs-2 (0.93) is lower than that of the catalyst N/S/F-CNTs obtained at $800^{\circ} \mathrm{C}$. It indicated that higher temperature made the heteroatom decomposed sharply, resulting in more defects and more active sites.

Figure 2 shows the XPS spectra of N, S, and F of N/S/FCNTs-2. There was an obvious peak at $689.4 \mathrm{eV}$ in the F1s peak of the catalyst, corresponding to the semi-ionic characteristic peak of C-F [9]. As shown in Figure 2, the $\mathrm{N} 1 \mathrm{~s}$ spectrum was deconvoluted to four peaks at 398.7, 399.6, 400.7, and $402.7 \mathrm{eV}$, belonging to pyridinic, pyrrolic, graphitic, and $\mathrm{NO}_{x}$, respectively. The $\mathrm{S} 2 \mathrm{p}$ characteristic peak can be deconvoluted to three peaks located at 162.2, 163.8 , and $168.9 \mathrm{eV}$, assigned to $\mathrm{S} 2 \mathrm{p}_{3 / 2}$ and $\mathrm{S} 2 \mathrm{p}_{1 / 2}$ of $\mathrm{C}-\mathrm{S}-\mathrm{C}$ 


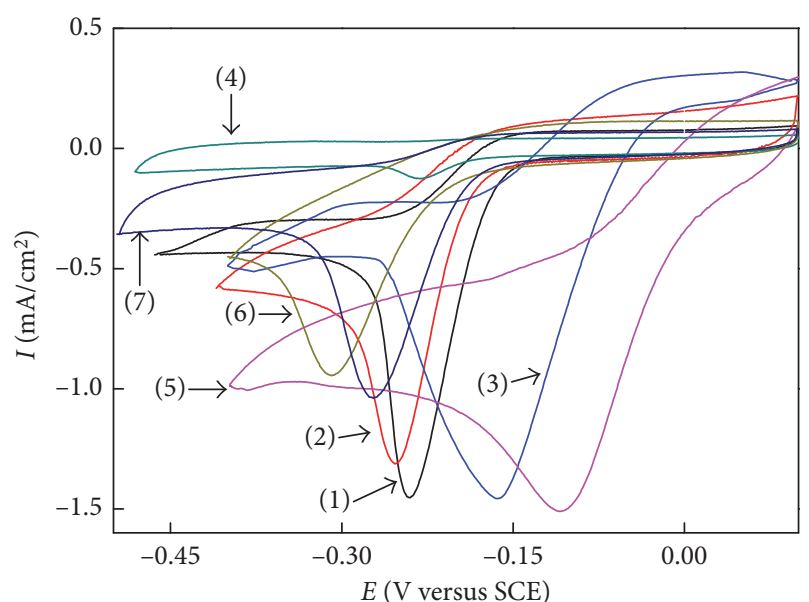

(a)

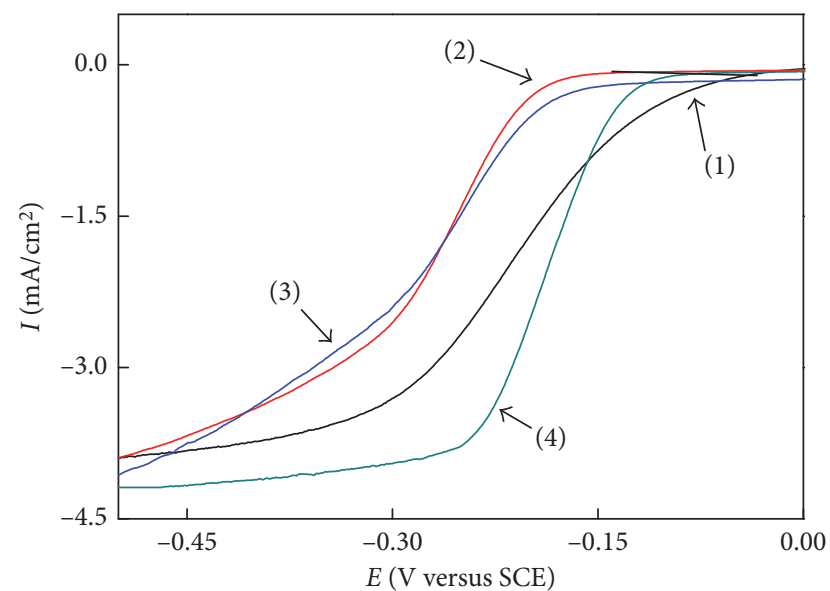

(b)

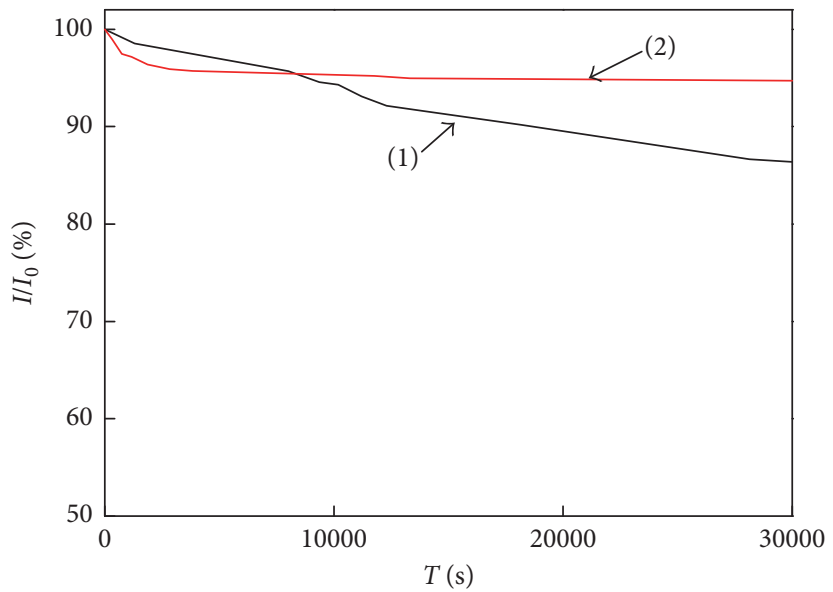

(c)

Figure 4: Electrochemical measurement of support and catalysts. (a) $\mathrm{CV}$ in $\mathrm{O}_{2}$ or $\mathrm{N}_{2}$-saturated $0.1 \mathrm{M} \mathrm{KOH}$ solution with a scan rate of $5 \mathrm{mV} \cdot \mathrm{s}^{-1}$ : (1) N/S-CNTs; (2) N/S/F-CNTs-2; (3) N/S/F-CNTs; (4) N/S/F-CNTs in N $\mathrm{N}_{2}$; (5) 20\% Pt/C; (6) MWCNTs; (7) N-CNTs. (b) LSV in $\mathrm{O}_{2}$-saturated $0.1 \mathrm{MKOH}$ solution at the rotation rate of $1600 \mathrm{rpm}$ with a scan rate of $10 \mathrm{mV} \cdot \mathrm{s}^{-1}$ : (1) $20 \% \mathrm{Pt} / \mathrm{C}$; (2) N/S/F-CNTs-2; (3) N/S-CNTs; (4) N/S/F-CNTs. (c) The current-time chronoamperometric response of catalysts: (1) 20\% Pt/C; (2) N/S/F-CNTs.

(thiophene-S) and $\mathrm{C}-\mathrm{SO}_{x}-\mathrm{C}$, respectively [21]. Among them, semi-ionic C-F, pyridinic $\mathrm{N}$, and thiophene-S were beneficial to improve the ORR performance. Besides, the multi-heteroatoms in the carbon material can form some non-electron-neutral sites because of the synergic effect $[22,23]$.

The formation process of catalysts was observed by TEM. The diameter of carboxylic MWCNT distribution is about $10-20 \mathrm{~nm}$, and its surface is flat (Figure 3(a)). However, the surface turned rough after deposition of the polydopamine nanofilm followed by the secondary reaction with $1 \mathrm{H}, 1 \mathrm{H}^{\prime}$, $2 \mathrm{H}, 2 \mathrm{H}^{\prime}$-perflurooctanethiol, and the thickness of the uneven surface is within the range of 5-13 nm (Figure 3(b)). Figure 3(c) shows that the thickness of the polymer film became thinner through pyrolysis to form N/S/F-CNTs, which is similar to that of N/S-CNTs (Figure 3(d)) and N-CNTs.

The cyclic voltammogram was measured to study the catalytic activity of electrocatalysts for ORR. It can be seen in Figure 4(a) that the reduction potential of MWCNTs was $-0.30 \mathrm{~V}$ with the current density of $-0.90 \mathrm{~mA} \cdot \mathrm{cm}^{-2}$.
The reduction potential of N-CNTs shifted positively to $-0.26 \mathrm{~V}$, and the current density increased. The reduction potential of N/S-CNTs $(-0.24 \mathrm{~V})$ was a little more positive than that of N-CNTs. The doped S would increase the electron density of carbon materials, and its electronegativity (2.58) was a little higher than that of $\mathrm{C}$ (2.55), which induced $\mathrm{C}$ atom containing a few positive charge to improve the activity of ORR. However, the thiophene-S content of PDCN was low, indicating that the activity of ORR did not improve greatly. In surprise, the reduction potential of N/S/F-CNTs shifted hugely up to $-0.16 \mathrm{~V}$, and the current increased to $-1.45 \mathrm{~mA} \cdot \mathrm{cm}^{-2}$. Compared with commercial $20 \% \mathrm{Pt} / \mathrm{C}$, it contained slightly lower reduction potential and higher current density. Electronegativity of F atom (3.98) was much higher than that of $\mathrm{C}$ atom, and the semi-ionic $\mathrm{C}-\mathrm{F}$ bond in N/S/F-CNTs presented higher activity than the C-F covalent bond [9]. The doped $\mathrm{F}$ improved the electron structure of carbon and increased the active site. As a result, the catalytic activity greatly improved, and it was even superior to that of N/S/F-CNTs-2, although the content of $S$ and $\mathrm{F}$ in N/S/F-CNTs-2 
was twice higher than that of N/S/F-CNTs. Compared with polydopamine treated under $800^{\circ} \mathrm{C}$, maybe $\mathrm{sp}^{2}$ of $\mathrm{C}$ in N/S/FCNTs-2 was much less likely to lead to poorer electrical conductivity, less defect, and lower activity [24]. Meanwhile, the reduction current of N/S/F-CNTs was weak in $\mathrm{N}_{2}$-saturated $0.1 \mathrm{M} \mathrm{KOH}$ solution. All the results showed that N/S/F-CNTs exhibited the highest catalytic activity.

Linear sweep voltammetry was carried out on the rotating disk electrode to analyze the reaction kinetics and catalytic mechanism for ORR. Figure 4(b) shows LSV of the catalysts under the rotating speed of $1600 \mathrm{rpm}$. Among the as-prepared catalysts, N/S/F-CNTs exhibited the highest onset potential $(-0.11 \mathrm{~V})$ that was more negative than that of $20 \% \mathrm{Pt} / \mathrm{C}(-0.07 \mathrm{~V})$, but its $E_{1 / 2}$ (half-wave potential, $-0.19 \mathrm{~V}$ ) was higher than that of $20 \% \mathrm{Pt} / \mathrm{C}(-0.21 \mathrm{~V})$. In addition, the LSV curve of N/S/F-CNTs showed wide current plateaus that started from $-0.25 \mathrm{~V}$ and highest current density in the diffusion-controlled region. Compared with N/S/F-CNTs, the other two catalysts exhibited evidently worse catalytic activity. The value of electron transfer number for N/S/F-CNTs was close to 4.0, which was calculated from Koutecky-Levich curves with a potential range of $-0.4 \mathrm{~V}$ to $-0.50 \mathrm{~V}$ [25-27]. The four electron pathway was preferred due to a fast rate of oxygen reduction $[28,29]$. Excellent stability of the electrocatalyst is very important for practical application [30]. Figure 4 (c) shows the stability of N/S/F-CNTs and $20 \%$ $\mathrm{Pt} / \mathrm{C}$. Both the current values decreased with the increase of time; however, the current attenuation of the catalyst $\mathrm{N} / \mathrm{S} / \mathrm{F}-\mathrm{CNT}$ displayed a slight current attenuation. $I / I_{0}$ of $\mathrm{Pt} / \mathrm{C}$ decreased to $86.5 \%$, while N/S/F-CNTs maintained $94.6 \%$ of the initial value in the same period. Clearly, the results showed that N/S/F-CNTs contained remarkable electrochemical stability.

\section{Conclusions}

In conclusion, $\mathrm{F}$ and other heteroatom codoped carbonbased catalysts for ORR were prepared successfully through polydopamine derivative followed by pyrolysis. Among the catalysts, N/S/F-CNTs exhibit excellent activity for ORR and remarkable electrochemical stability, which is comparable with commercially expensive $20 \% \mathrm{Pt} / \mathrm{C}$. In addition, PDA can be deposited on any substrate surface and react with organic molecules through Schiff base or Michael addition reactions or coordinate with metal ions. So, PDA is a good building block for designing multi-heteroatom-doped or metal-nitrogen-carbon materials.

\section{Conflicts of Interest}

The authors declare that there are no conflicts of interest regarding the publication of this paper.

\section{Acknowledgments}

This work was supported by the National Science Foundation of China (21401204 and 61401149).

\section{References}

[1] G. C. Liu, X. N. Ding, H. W. Zhou et al., "Structure optimization of cathode microporous layer for direct methanol fuel cells," Applied Energy, vol. 147, pp. 396-401, 2015.

[2] F. Ye, C. Xu, G. C. Liu et al., "A novel PtRuIr nanoclusters synthesized by selectively electrodepositing Ir on PtRu as highly active bifunctional electrocatalysts for oxygen evolution and reduction," Energy Conversion and Management, vol. 155, pp. 182-187, 2018.

[3] F. Ye, L. Chen, J. J. Li, J. L. Li, and X. D. Wang, "Shapecontrolled fabrication of platinum electrocatalyst by pulse electrodeposition," Electrochemistry Communications, vol. 10, no. 3, pp. 476-479, 2008.

[4] D. S. Yu, Q. Zhang, and L. M. Dai, "Highly efficient metal-free growth of nitrogen-doped single-walled carbon nanotubes on plasma-etched substrates for oxygen reduction," Journal of the American Chemical Society, vol. 132, no. 43, pp. 15127-15129, 2010.

[5] K. Waki, R. A. Wong, H. S. Oktaviano et al., "Non-nitrogen doped and non-metal oxygen reduction electrocatalysts based on carbon nanotubes: mechanism and origin of ORR activity," Energy \& Environmental Science, vol. 7, no. 6, pp. 1950-1958, 2014.

[6] D. H. Guo, R. Shibuya, C. Akiba, S. Saji, T. Kondo, and J. Nakamura, "Active sites of nitrogen-doped carbon materials for oxygen reduction reaction clarified using model catalysts," Science, vol. 351, no. 6271, pp. 361-365, 2016.

[7] L. J. Yang, S. J. Jiang, Y. Zhao et al., "Boron-doped carbon nanotubes as metal-free electrocatalysts for the oxygen reduction reaction," Angewandte Chemie International Edition, vol. 50, no. 31, pp. 7132-7135, 2011.

[8] S. Chen, J. Y. Bi, Y. Zhao et al., "Nitrogen-doped carbon nanocages as efficient metal-free electrocatalysts for oxygen reduction reaction," Advanced Materials, vol. 24, no. 41, pp. 5593-5597, 2012.

[9] X. J. Sun, Y. W. Zhang, P. Song et al., "Fluorine-doped carbon blacks: highly efficient metal-free electrocatalysts for oxygen reduction reaction," ACS Catalysis, vol. 3, no. 8, pp. 17261729, 2013.

[10] D. S. Yang, D. Bhattacharjya, S. Inamdar, J. Park, and J. S. Yu, "Phosphorus-doped ordered mesoporous carbons with different lengths as efficient metal-free electrocatalysts for oxygen reduction reaction in alkaline media," Journal of the American Chemical Society, vol. 134, no. 39, pp. 16127-16130, 2012.

[11] S. B. Yang, L. J. Zhi, K. Tang, X. L. Feng, J. Maier, and K. Müllen, "Efficient synthesis of heteroatom (N or S)-doped graphene based on ultrathin graphene oxide-porous silica sheets for oxygen reduction reactions," Advanced Functional Materials, vol. 22, no. 17, pp. 3634-3640, 2012.

[12] W. H. Niu, L. G. Li, X. J. Liu et al., "Mesoporous N-doped carbons prepared with thermally removable nanoparticle templates: an efficient electrocatalyst for oxygen reduction reaction," Journal of the American Chemical Society, vol. 137, no. 16, pp. 5555-5562, 2015.

[13] S. A. Wohlgemuth, R. J. White, M. G. Willinger, M. M. Titirici, and M. Antonietti, "A one-pot hydrothermal synthesis of sulfur and nitrogen doped carbon aerogels with enhanced electrocatalytic activity in the oxygen reduction reaction," Green Chemistry, vol. 14, no. 5, pp. 1515-1523, 2012.

[14] Z. W. Liu, M. Li, F. Wang, and Q. D. Wang, "Novel As-doped, As and $\mathrm{N}$-codoped carbon nanotubes as highly active and durable electrocatalysts for $\mathrm{O}_{2}$ reduction in alkaline medium," Journal of Power Sources, vol. 306, pp. 535-540, 2016. 
[15] Y. J. Gong, H. Fei, X. L. Zou et al., "Boron- and nitrogensubstituted graphene nanoribbons as efficient catalysts for oxygen reduction reaction," Chemistry Materials, vol. 27, no. 4, pp. 1181-1186, 2015.

[16] C. H. Choi, S. H. Park, and S. I. Woo, "Binary and ternary doping of nitrogen, boron, and phosphorus into carbon for enhancing electrochemical oxygen reduction activity," ACS Nano, vol. 6, no. 8, pp. 7084-7091, 2012.

[17] Y. F. Zhan, J. L. Huang, Z. P. Lin et al., "Iodine/nitrogen codoped graphene as metal free catalyst for oxygen reduction reaction," Carbon, vol. 95, pp. 930-939, 2015.

[18] J. Yang, L. H. Niu, Z. J. Zhang, J. Zhao, and L. J. Chou, "Electrochemical behavior of a polydopamine nanofilm," Analytical Letters, vol. 48, no. 13, pp. 2031-2039, 2015.

[19] H. Lee, S. M. Dellatore, W. M. Miller, and P. B. Messersmith, "Mussel-inspired Surface chemistry for multifunctional coatings," Science, vol. 318, no. 5849, pp. 426-430, 2007.

[20] K. G. Qu, Y. Zheng, S. Dai, and S. Z. Qiao, "Graphene oxidepolydopamine derived $\mathrm{N}, \mathrm{S}$-codoped carbon nanosheets as superior bifunctional electrocatalysts for oxygen reduction and evolution," Nano Energy, vol. 19, pp. 373-381, 2016.

[21] C. V. Rao, C. R. Cabrera, and Y. Ishikawa, "In search of the active site in nitrogen-doped carbon nanotube electrodes for the oxygen reduction reaction," Journal of Physical Chemistry Letters, vol. 1, no. 18, pp. 2622-2627, 2010.

[22] X. Z. Song, H. X. Ren, J. J. Ding, C. F. Wang, X. Yin, and H. W. Wang, "One-step nanocasting synthesis of sulfur and nitrogen co-doped ordered mesoporous carbons as efficient electrocatalysts for oxygen reduction," Materials Letters, vol. 159, pp. 280-283, 2015.

[23] W. H. Lee, J. W. Suk, H. Chou et al., "Selective-area fluorination of graphene with fluoropolymer and laser irradiation," Nano Letters, vol. 12, no. 5, pp. 2374-2378, 2015.

[24] K. L. Ai, Y. L. Liu, C. P. Ruan, L. H. Lu, and G. Q. Lu, "Sp" C-dominant N-doped carbon sub-micrometer spheres with a tunable size: a versatile platform for highly efficient oxygenreduction catalysts," Advanced Materials, vol. 25, no. 7, pp. 998-1003, 2013.

[25] Y. Nie, X. H. Xie, S. G. Chen et al., "Towards effective utilization of nitrogen-containing active sites: nitrogen-doped carbon layers wrapped CNTs electrocatalysts for superior oxygen reduction," Electrochimica Acta, vol. 187, pp. 153-160, 2016.

[26] Z. L. Li, G. L. Li, L. H. Jiang et al., "Ionic liquids as precursors for efficient mesoporous iron-nitrogen-doped oxygen reduction electrocatalysts," Angewandte Chemie International Edition, vol. 54, no. 5, pp. 1494-1498, 2015.

[27] Q. Li, G. Wu, D. A. Cullen et al., "Phosphate-tolerant oxygen reduction catalysts," ACS Catalysis, vol. 4, no. 9, pp. 31933200, 2014.

[28] Y. T. Sang, A. P. Fu, H. Li, and Z. G. Pei, "Experimental and theoretical studies on the effect of functional groups on carbon nanotubes to its oxygen reduction reaction activity," Colloids and Surfaces A: Physicochemical and Engineering Aspects, vol. 506, pp. 476-484, 2016.

[29] S. Yuvaraj, A. Vignesh, S. Shanmugam, and R. K. Selvan, "Nitrogen-doped multi-walled carbon nanotubes- $\mathrm{MnCo}_{2} \mathrm{O}_{4}$ microsphere as electrocatalyst for efficient oxygen reduction reaction," International Journal of Hydrogen Energy, vol. 41, no. 34, pp. 15199-15207, 2016.

[30] Z. W. Liu, M. Li, F. Wang, and Q. D. Wang, "Novel As-doped, As and $\mathrm{N}$-codoped carbon nanotubes as highly active and durable electrocatalysts for $\mathrm{O}_{2}$ reduction in alkaline medium," Journal of Power Sources, vol. 306, pp. 535-540, 2016. 


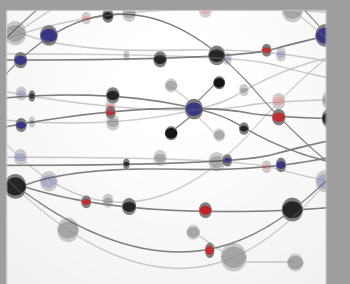

The Scientific World Journal
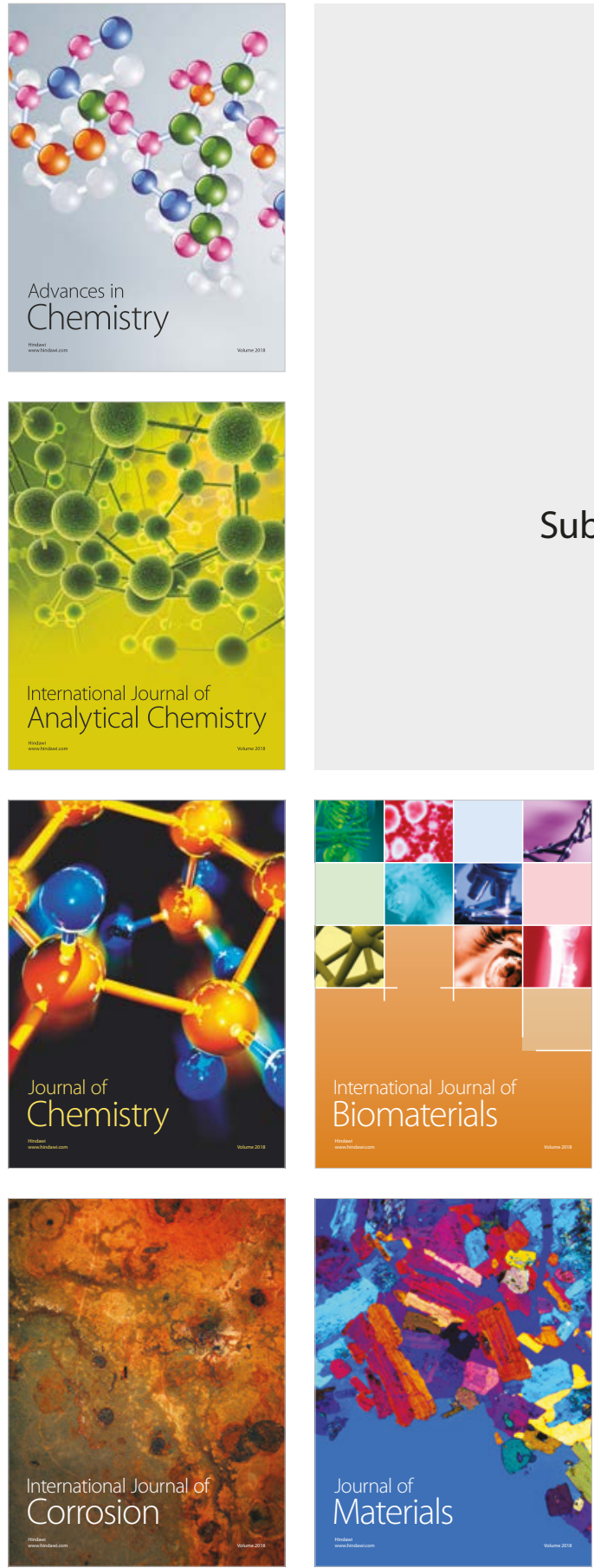

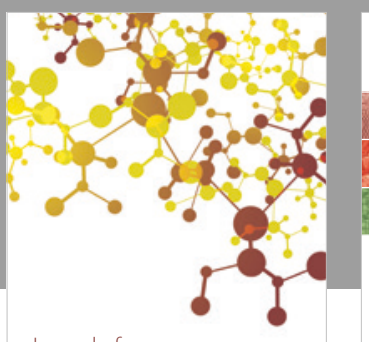

Journal of

Applied Chemistry
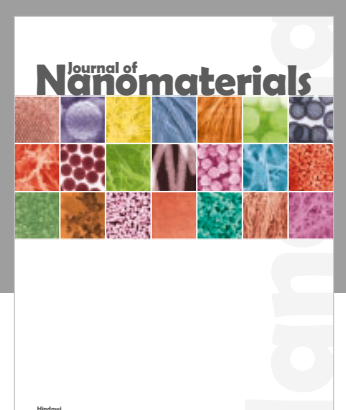

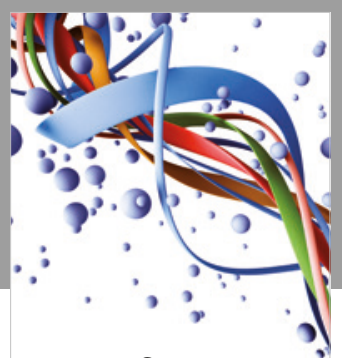

Scientifica

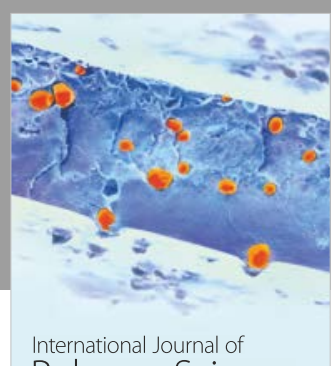

Polymer Science

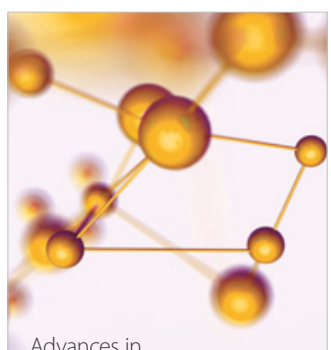

Physical Chemistry
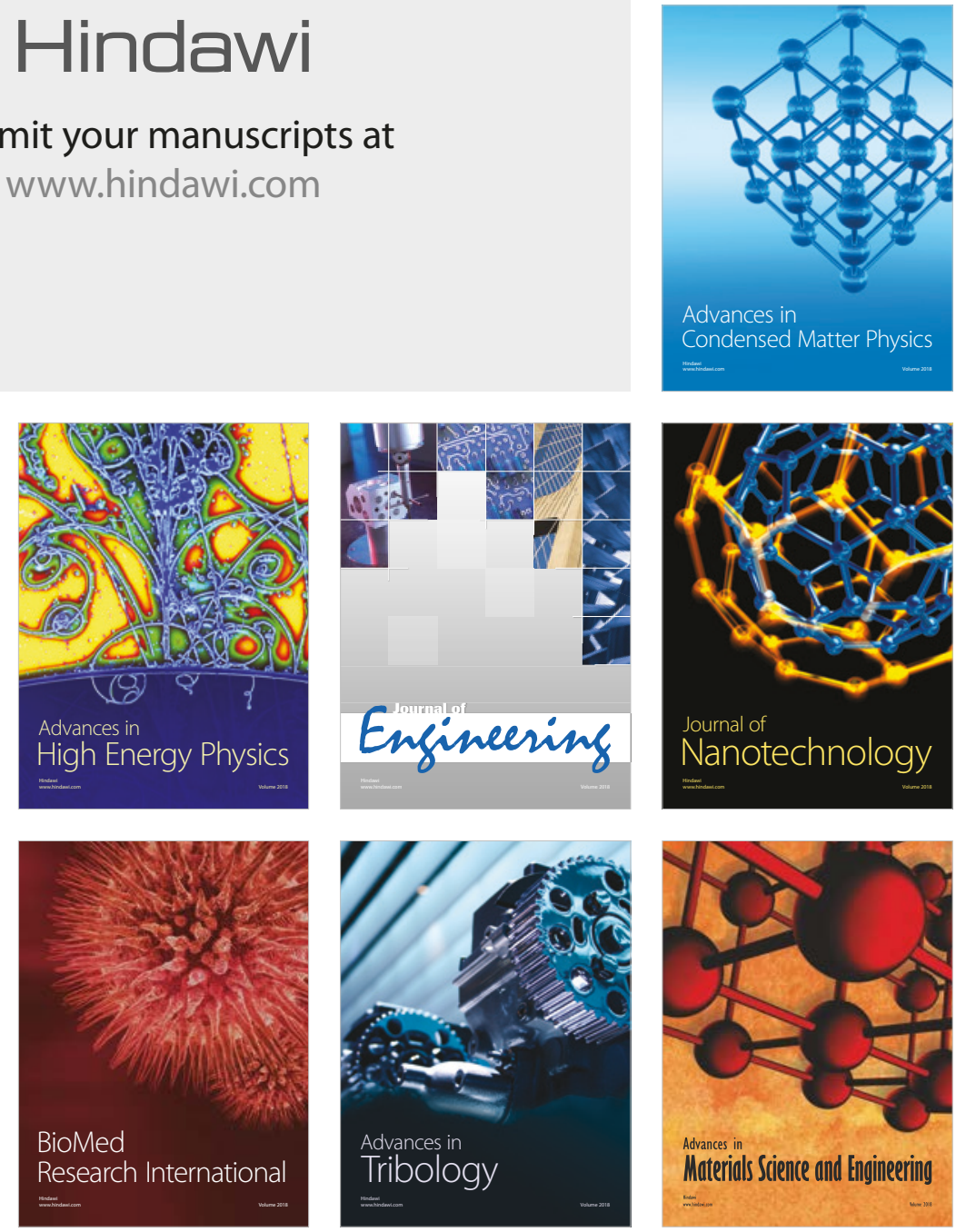